\title{
ANALYSIS OF FOETAL AUTOPSY RESULTS IN A TERTIARY HEALTH CARE DELIVERY CENTRE IN SOUTH INDIA
}

\author{
Shali A. $S^{1}$, Feroze $M^{2}$ \\ ${ }^{1}$ Assistant Professor, Department of Pathology, Government Medical College, Calicut, \\ 2Professor, Department of Pathology, Government Medical College, Trichur.
}

\begin{abstract}
BACKGROUND

Congenital anomalies form the most common cause for foetal losses in pregnancy. Foetal autopsy studies clinico-pathological and cytogenetic aspects of the foetal death, which are extremely important in the prevention of anomalies in future pregnancies.

\section{MATERIALS AND METHODS}

All foetuses of medically terminated pregnancies following detection of foetal anomalies, still-born babies during second and third trimesters and foetal deaths in the early neonatal period that took place in Institute of Maternal and Child Health, Calicut Medical College during a two-year period from January 2011 to December 2012 were included in the study. A full foetal autopsy was conducted in all cases. Analysis was done on 49 foetal autopsies performed on such cases.
\end{abstract}

\section{RESULTS}

The mean gestational age of the foetuses was 26.9 weeks with $59.1 \%$ being below the age of 28 weeks. The mean age of the mothers in our study was 24.4 years with $49 \%$ belonging to the age group of 21 - 25 years; $41 \%$ of mothers had some bad past obstetric history; $57.1 \%$ of the foetuses had multiple anomalies. Isolated anomalies were found only in $24.5 \%$. Facial dysmorphism was the commonest anomaly detected seen in 30.6\% followed by skeletal abnormalities found in $24.4 \%$; $65.3 \%$ of cases had anomalies detected by histopathological examination; $14.3 \%$ each belonging to renal system and respiratory system. Congenital lobar emphysema was the commonest anomaly detected by histopathological examination. There were 5 cases of multiple malformations in the study that fit into multiple malformation syndromes.

\section{CONCLUSION}

The value of post-mortem examinations of foetus is well recognised and it is a powerful tool in clinical medicine in providing a pathological classification of foetal death. This study has analysed the causes of in utero foetal demise and the utility of perinatal autopsy in identifying the cause of death.

\section{KEYWORDS}

Foetal Autopsy, Congenital Anomalies, Histopathology, Malformation Syndromes.

HOW TO CITE THIS ARTICLE: Shali AS, Feroze M. Analysis of foetal autopsy results in a tertiary health care delivery centre in South India. J. Evolution Med. Dent. Sci. 2017;6(24):2046-2049, DOI: 10.14260/Jemds/2017/446

\section{BACKGROUND}

The value of post-mortem examinations of foetus is well recognised since the contributions of Potter and Morrison in achieving a pathological classification of foetal death. Congenital malformations remain a major feature of foetal death and range from $10 \%-25 \%$ in various studies. Perinatal death brings in a lot of trauma to the family. Common causes for perinatal death in our country are congenital malformations, infections, trauma, asphyxia, etc. Congenital anomalies cause around $10 \%-15 \%$ of perinatal death in India. Many causes for the perinatal loss are likely to recur and the future reproductive decision of the couple depends on the cause of the foetal loss, which will predict the recurrence risk. Finding the risk factor involved provides an option for preventing further similar mishap in the family.

Financial or Other, Competing Interest: None.

Submission 14-02-2017, Peer Review 11-03-2017,

Acceptance 18-03-2017, Published 23-03-2017.

Corresponding Author:

Dr. Shali A. $S$,

Brindavan,

Chevayur,

Kozhikode-17.

E-mail: shalidr@gmail.com

DOI: $10.14260 /$ jemds $/ 2017 / 446$

(c) (i) $(5)$
The recurrence risk depends upon the aetiology of the anomaly- whether genetic or not- and this can range from 0 to $25 \%$.[1],[2],[3]

Anomalies can be malformations, deformations, dysplasias or disruptions.[4] Antenatal transabdominal/ vaginal ultrasonography is very important for the early diagnosis, and termination of a pregnancy with serious anomalies.[5] Perinatal autopsy of the foetus is another very important evaluation modality for the precise diagnosis of the associated anomalies and to confirm the diagnosis. It is more accurate in assessment of the congenital malformations and discovers new lesions including the iatrogenic ones.

Very few studies have been documented in India regarding the distribution of the congenital malformations. Hence, this study is undertaken with a view to describe the morphological spectrum of foetal losses during pregnancy and in early neonatal period.

\section{MATERIALS AND METHODS}

All foetuses of medically terminated pregnancies following detection of foetal anomalies, still born babies during second and third trimesters and foetal deaths in the early neonatal period that took place in Institute of Maternal and Child Health, Calicut Medical College during a two-year period from 
January 2011 to December 2012 were included in the study. Analysis was done on 49 autopsies performed on such cases.

We received the specimens from Department of Obstetrics and Gynaecology, Calicut Medical College. All the data about the previous pregnancy, maternal age, gestational week at the time of USG diagnosis, termination of pregnancy if any, medical history and family history were collected from the patients records. Consent was taken from the parents.

A detailed general examination was done in each case. Photographs of the external appearance were taken in all cases. Radiological evaluation with x-ray was done whenever possible and the findings recorded.

All the measurements like Weight, Crown Rump Length, Head Circumference and Chest Circumference were noted. Autopsy was done by a midline Y-shaped incision. All the serous cavities were checked for any fluid. All the gross abnormalities of each system were checked. A detailed description of autopsy findings was recorded as per the proforma prepared. In cases where any abnormality was noted, an extensive sampling was done from that area. Representative bits were taken from all organs if no abnormalities were noted. After grossing, slides were prepared with haematoxylin and eosin stain and used to correlate with gross morphology. Special stains were done in indicated cases.

\section{RESULTS}

Out of the 49 autopsies done, 21 were in the second trimester and 19 in the third trimester; 9 were neonates. The highest number was in the age of 21 to 24 weeks (20.4\%) and 59.1\% were below the gestational age of 28 weeks. (Mean 26.9 weeks).

$49 \%$ of the mothers were between the ages of 21 and 25 years and $94 \%$ were below the age of 30 years. The mean age was 24.4 years. There was no one above the age of 40 years. While 20 mothers were primi, 9 had previous normal delivery; $41 \%$ of the mothers had some bad past obstetric history. History of foetal loss like abortions, stillbirth and neonatal death was obtained in 26 of the cases. Congenital diseases and malformations of previous children were seen in 3 cases.

Morphological examination was conducted in all cases by complete autopsy as per the protocol. While 9 cases did not show any abnormalities, 12 cases showed only isolated anomalies in which only a single body region was affected. The remaining 28 cases showed multiple anomalies that affected more than one body region. Many of the cases had more than one anomaly, so that the number of anomalies added up to more than 28. A system wise classification showed that facial dysmorphism was the commonest anomaly in our study seen in $30.6 \%$ of cases followed by skeletal abnormalities seen in $24.4 \%$ of cases. The system wise breakup of the anomalies is given in the chart below.

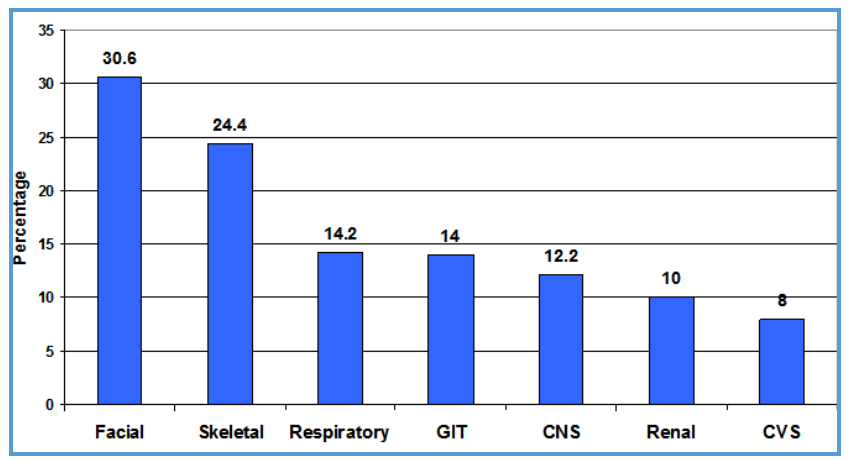

Chart 1. System Wise Breakup of the Anomalies

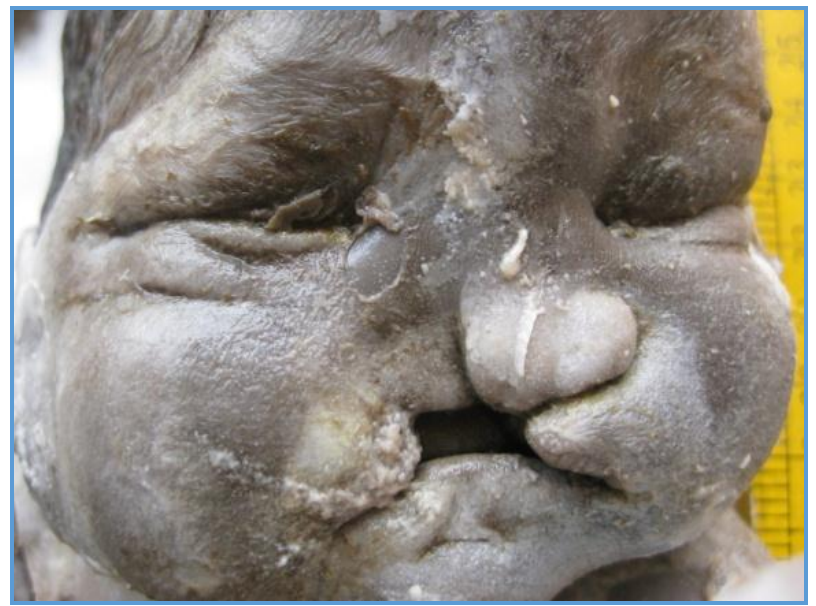

Figure 1. Fascial Dysmorphism

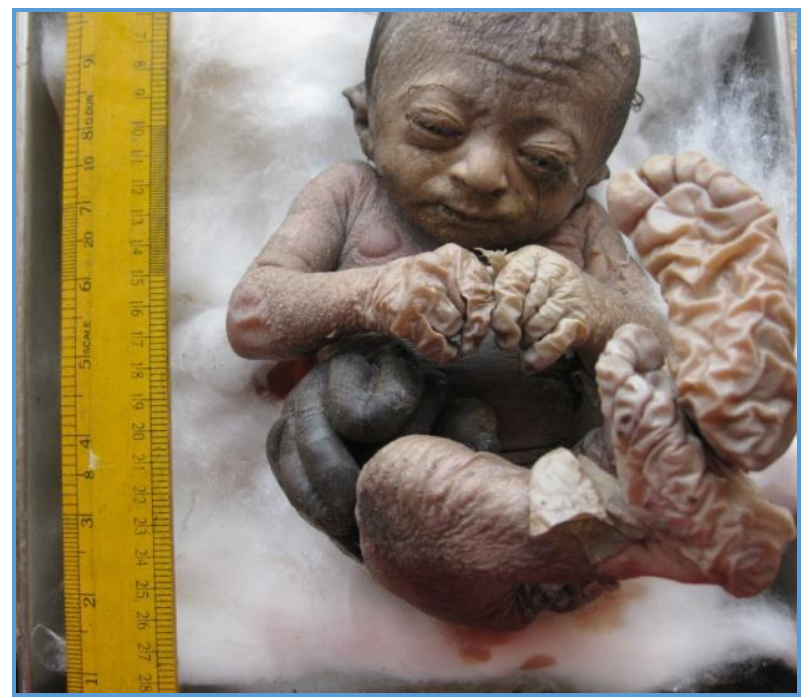

Figure 2. Gastroschisis

Histopathological examination was done in all cases. Bits were taken from all organs irrespective of whether they were grossly abnormal or not. There were 7 cases each involving the respiratory system and renal system. The lesions are shown in the table below. 


\begin{tabular}{|c|c|c|c|}
\hline Lesion & No. & $\%$ & Associated Anomalies \\
\hline Lungs & 7 & 14.3 & \\
\hline $\begin{array}{c}\text { Congenital lobar } \\
\text { emphysema }\end{array}$ & 4 & & $\begin{array}{l}\text { Renal agenesis (2) } \\
\text { anencephaly }\end{array}$ \\
\hline $\begin{array}{l}\text { Congenital cystic } \\
\text { adenomatoid } \\
\text { malformation }\end{array}$ & 1 & & Myocardial hypertrophy \\
\hline Hypoplastic lungs & 1 & & nil \\
\hline Lung cyst & 1 & & $\begin{array}{l}\text { Infantile polycystic kidney } \\
\text { disease }\end{array}$ \\
\hline Renal & 7 & 14.3 & \\
\hline Renal agenesis & 4 & & $\begin{array}{c}\text { Congenital lobar } \\
\text { emphysema (2) } \\
\text { CTEV and imperforate anus } \\
\text { hydrocephalus }\end{array}$ \\
\hline Renal cyst & 1 & & Single atria and ventricle \\
\hline $\begin{array}{l}\text { Infantile polycystic } \\
\text { kidney disease }\end{array}$ & 1 & & $\begin{array}{l}\text { Lung cysts } \\
\text { Liver cysts }\end{array}$ \\
\hline $\begin{array}{c}\text { Dilated urinary } \\
\text { bladder with mega } \\
\text { ureters } \\
\end{array}$ & 1 & & Nil \\
\hline Cardiac anomalies & 4 & 8.2 & \\
\hline $\begin{array}{l}\text { Single atria and } \\
\text { ventricle }\end{array}$ & 1 & & Renal cysts \\
\hline $\begin{array}{l}\text { Myocardial } \\
\text { hypertrophy }\end{array}$ & 3 & & $\begin{array}{c}\text { Placental haematoma, } \\
\text { Hydrocephalus, } \\
\text { Congenital adenomatoid } \\
\text { malformation } \\
\end{array}$ \\
\hline Abdominal & 6 & 12.2 & \\
\hline $\begin{array}{l}\text { Small intestinal } \\
\text { stenosis/atresia }\end{array}$ & 3 & & $\begin{array}{c}\text { Hemivertebrae } \\
\text { Facial dysmorphism } \\
\text { Cardiac muscle hypertrophy }\end{array}$ \\
\hline Intestinal infarction & 1 & & Gastroschisis \\
\hline Liver cyst & 1 & & $\begin{array}{l}\text { Infantile polycystic kidney } \\
\text { disease }\end{array}$ \\
\hline $\begin{array}{l}\text { Diaphragmatic } \\
\text { hernia }\end{array}$ & 1 & & \\
\hline Others & 6 & 12.2 & \\
\hline Scalp haemangioma & 1 & & Nil \\
\hline Spinal haemangioma & 1 & & $\begin{array}{l}\text { Hydrocephalus } \\
\text { Meningomyelocele }\end{array}$ \\
\hline Lymphangioma & 1 & & Nil \\
\hline $\begin{array}{l}\text { Storage disorder- } \\
\text { liver and heart }\end{array}$ & 1 & & Nil \\
\hline $\begin{array}{l}\text { Hydrops foetalis- } \\
\text { unknown cause }\end{array}$ & 2 & 4.1 & Nil \\
\hline \multicolumn{4}{|c|}{$\begin{array}{c}\text { Table 1. Anomalies detected } \\
\text { after Histopathology Examination }\end{array}$} \\
\hline
\end{tabular}

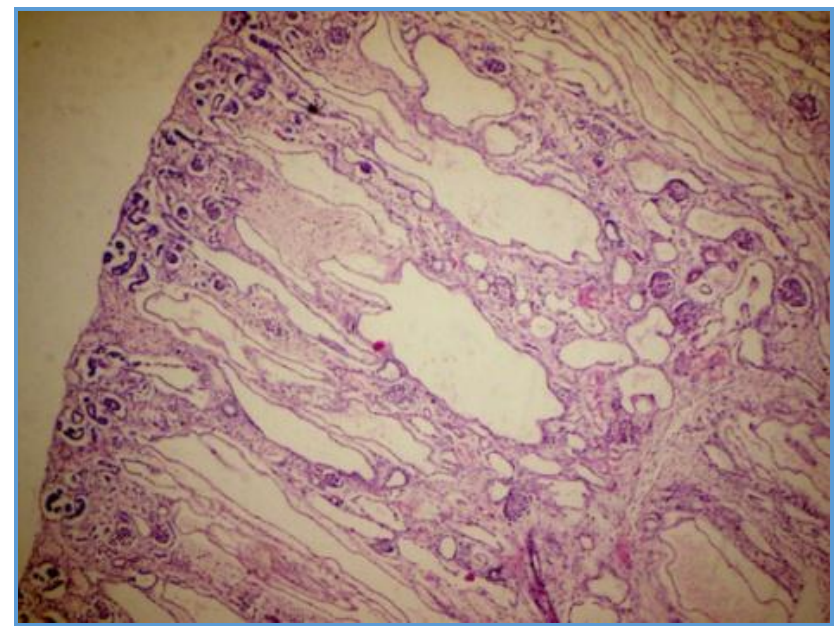

Figure 3. Infantile Polycystic Kidney Disease

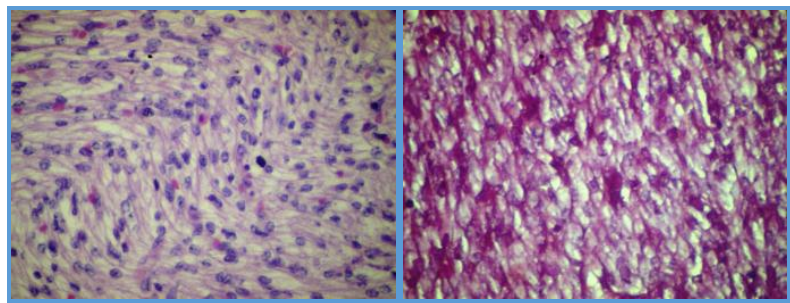

Figure 4. Mucolipidosis Myocardium (H \& E, PAS)

Placenta was received in 12 cases along with the autopsy specimen, 3 of which showed placental haematoma, placental infarct and placental necrosis and calcification. Placental haematoma showed an association with myocardial hypertrophy.

\section{DISCUSSION}

The value of post-mortem examinations of foetus is wellrecognised since the contributions of Potter and Morrison in providing a pathological classification of foetal death. Congenital malformations remain a major feature of foetal death and range from 10\% - 25\% in different studies. A study done by Saller DN et al in 1995[1] showed that autopsy added significantly to the clinical diagnosis in $44.7 \%$ of the cases. In $55.3 \%$ cases, the antenatal diagnosis was confirmed on autopsy. In 1996, an Indian study done by Rajashekar et al[2] found that autopsy added to or changed the preexisting diagnosis in $59.5 \%$ of the cases. This study has tried to analyse the causes of in utero foetal demise, and the utility of perinatal autopsy in identifying the cause of death. Very few studies have been documented in India regarding the distribution of congenital malformations. Hence, this study is undertaken with a view to describe the morphological spectrum of foetal losses during pregnancy and in early neonatal period.

Analysis of the gestational age of our cases showed that $42.9 \%$ were in the second trimester and $38.8 \%$ in the third trimester with a mean gestational age of 26.9 weeks. It was much higher in studies by Nayak et al[6] conducted in Mangalore, in which $57.1 \%$ of foetuses were in the age group of 26 to 38 weeks and also in the published data in Potter's Pathology of foetus in which two-thirds of all foetal deaths were above the age of 28 weeks. Another study conducted in Kottayam also showed a higher age group of foetal deaths, where majority of foetuses was in the 37 - 41 weeks group. [7]

The sex distribution of the foetuses in our study was almost 1:1. Sunethri Padma in Hyderabad found that of the 28 cases of foetuses with congenital anomalies, 18 were males with a sex ratio of 1.7:1 in favour of males.[8]

In our study $49 \%$ of the mothers of these babies were in the age group of 21 - 25 years, while that in the Nayak study[6] $35.7 \%$ of mothers were between 25 to 30 years old. However, in Maharashtra, Vikram Datta found that mothers of babies with congenital malformations were mostly in the age group of 21 - 25 years as in our study.[9] The mean age in our study was only 24.4 years, thus undermining the fact that increasing maternal age contributes to increased incidence of congenital anomalies.

Gestational hypertension was the most common associated condition with foetal death in our study constituting $6 \%$ of cases. Nayak[6] from Mangalore found $28.6 \%$ association with gestational hypertension, while Korejo[10] in the study conducted in Karachi could find an association in $24 \%$. 
In this study isolated anomalies were seen in $24.5 \%$ only, while $57.1 \%$ had multiple anomalies. This is far less than the $58.6 \%$ of isolated anomalies showed in study conducted by Sankar et al.[11] Interestingly, 30.7\% of isolated anomalies were recognised after the internal examination, thereby underscoring the importance of internal examination during foetal autopsy; 5 out of the 12 cases with isolated anomalies in our study could be diagnosed only after the internal examination. There were one case each of bilateral renal agenesis, lung hypoplasia, dilated bladder with mega ureters, congenital diaphragmatic hernia and single umbilical artery.

Of the 2 cases of single umbilical artery we had in our study, one was an isolated anomaly while the other was associated with ventricular hypertrophy and hydrocephalus. Single umbilical artery is known to be associated with other foetal anomalies. Even when there was no specific pattern in the occurrence of associated anomalies, there was a predominance of cardiovascular and urogenital anomalies. [12]

Causes of non-immune hydrops foetalis are numerous including chromosomal anomalies, haematological disorders, metabolic disorders and cardiovascular disorders. ${ }^{[13]}$ The other common cause of hydrops is infections (12\% - 16\%). In our study, out of two cases of hydrops foetalis, one gave a history of chicken pox and hypertension in the mother during antenatal period.

A system wise classification of the anomalies in our study showed that facial dysmorphism was the commonest anomaly followed by skeletal abnormalities. Sunethri Padma, and Ramakrishna D in their study showed that the most common anomalies were that of central nervous system [44\%] with anencephaly being the commonest one (50\%).[8] In our study, CNS was involved only in $12.2 \%$ with only one case of anencephaly. In a study conducted in Kerala,[7] $12 \%$ of late foetal death and $15 \%$ of early neonatal death were due to congenital malformations. Important congenital malformations included anencephaly, multiple congenital anomalies, hydrocephalus, omphalocoele and cystic hygroma.

Identification of single-gene autosomal recessive malformation syndrome is important as the recurrence risk in this situation is $25 \%{ }^{[14]}$ We had one case of autosomal recessive polycystic kidney. On histopathological study, the kidney with ARPKD displayed numerous dilated and elongated tubular structures, radially oriented relative to the renal hilum (Fig. 3). Our case was associated with lung cysts and liver cysts.

Histopathology examination of placenta is of great importance in cases without malformations, because it may provide cause of death in stillbirth or neonatal death. In our series, placenta was available only in 12 cases. In one of our case, placenta showed extensive areas of necrosis and calcification. However, there were no findings suggestive of any infection. The mother in that case was Rh -ve. But no such association has been described so far. Aparecida G. P. Garcia[15] described the placenta showing necrotic lesions, both on gross and microscopic examination, examined in two cases of alastrim and one of chickenpox. On the surface and on the cut section there were numerous minute, irregularly spread yellowish areas.

\section{CONCLUSION}

The value of post-mortem examinations of foetus is wellrecognised and it is a powerful tool in clinical medicine in providing a pathological classification of foetal death. This study has analysed the causes of in utero foetal demise and the utility of perinatal autopsy in identifying the cause of death.

A system wise classification of the anomalies in our study showed that facial dysmorphism was the commonest anomaly followed by skeletal abnormalities.

Histopathology, especially of placenta is of great importance in cases without malformations, because it may provide cause of death in stillbirth or neonatal death.

\section{REFERENCES}

[1] Saller ND, Lesser BK, Harrel U, et al. The clinical utility of the perinatal autopsy. JAMA 1995;273(8):663-5.

[2] Rajasekhar S, Bhat VB, Veliath AJ, et al. Perinatal autopsy - a seven year study. Indian J Pediatr 1996;63:511-6.

[3] Chitty LS, Hunt GH, Moore J, et al. Effectiveness of routine ultrasonography in detecting fetal structural abnormalities in a low-risk population. BMJ 1991;303(6811):1165-9.

[4] Saari-Kemppainen A, Karjalainen O, Ylostalo P, et al. Ultrasound screening and perinatal mortality: controlled trial of systematic one-stage screening in pregnancy. The helsinki ultrasound trial. Lancet 1990;336(8712):387-91.

[5] Levi S. Ultrasound in prenatal diagnosis: polemics around routine ultrasound screening for secondtrimester fetal malformations. Prenat Diagn 2002;22(4):285-95.

[6] Nayak SR, Nidhi G. Determinations of antepartum fetal death. J Obstet Gynecol India 2010;60(6):494-7.

[7] Pradeep M, Rajam L, Sudevan P. Perinatal mortality-a hospital based study. Indian Pediatr 1995;32(10):1091-4.

[8] Padma S, Devaki R, Jijiyabai P, et al. Pattern of distribution of congenital anomalies in stillborn: a hospital based prospective study. International Journal of Pharma and Bio Sciences 2011;2(2):604-10.

[9] Datta V, Chaturvedi P. Congenital malformations in rural Maharashtra. Indian Pediatrics 2000;37(9):9981001.

[10] Korejo R, Bhutta S, Noorani KJ, et al. An audit and trends of perinatal mortality at the Jinnah postgraduate medical center, Karachi. J Pak Med Assoc 2007;57(4):168-72.

[11] Sankar VH, Phadke SR. Clinical utility of fetal autopsy and comparison with prenatal ultrasound findings. J Perinatol 2006;26(4):224-9.

[12] Gaikwad NB, Waghmare VKR, Gaikwad RB, et al. Congenital anomalies associated with the single umbilical artery: an ultra sonography study. J Basic Appl Sci Res 2012;2(2):1278-80.

[13] Steiner RD. Hydrops fetalis: role of the geneticist. Semin Perinatol 1995;19(6):516-24.

[14] Desmet V. Congenital diseases of intrahepatic bile ducts: variations on the theme ductal plate malformation. Hepatology 1992;16(4):1069-83.

[15] Garcia AG. Fetal infection in chickenpox and alastrim, with histopathologic study of the placenta. Pediatrics 1963;32(5):895-901. 